\title{
Multi-scale characterisation of chars mineral species for tar cracking
}

\author{
Maxime Hervy $^{\mathrm{a}, \mathrm{b}, *}$, Sarah Berhanu ${ }^{\mathrm{c}}$, Elsa Weiss-Hortala ${ }^{\mathrm{b}}$, Anthony Chesnaud ${ }^{\mathrm{c}}$, Claire Gérente ${ }^{\mathrm{a}}$, \\ Audrey Villot ${ }^{\mathrm{a}}$, Doan Pham Minh ${ }^{\mathrm{b}}$, Alain Thorel $^{\mathrm{c}}$, Laurence Le Coq ${ }^{\mathrm{a}}$, Ange Nzihou ${ }^{\mathrm{b}}$ \\ ${ }^{a}$ Ecole des Mines de Nantes, GEPEA UMR CNRS 6144, 4 rue A. Kastler, BP 20722, 44307 Nantes Cedex 03, France \\ ${ }^{\mathrm{b}}$ Université de Toulouse, Mines Albi, CNRS, Centre RAPSODEE, Campus Jarlard, Route de Teillet, F.81013 Albi Cedex 09, France \\ ${ }^{\mathrm{C}}$ MINES ParisTech, PSL Research University, MAT - Centre des matériaux, CNRS UMR 7633, BP 87, 91003 Evry, France
}

\begin{abstract}
A B S T R A C T
Syngas from thermochemical conversion of waste or biomass is a renewable energy carrier that may contain pollutants - such as tar - that should be removed before further syngas utilisation. Chars have proved to be promising catalysts for tar cracking, but the influence of the physico-chemical properties on their reactivity is still unclear. This work aimed to better understand the structure and the composition of the mineral species of pyrolysis char, as well as their catalytic role in tar cracking. For this purpose, a characterisation of the minerals has been performed at bulk, surface (studied at micro and nano-scale) and crystallite scale. Pyrolysis chars were produced from wastes generated on cruise ships - namely used wood pallets (UWP), food waste (FW) and coagulation flocculation sludge (CFS) - having different mineral amount and content. Ethylbenzene was used as surrogate of light aromatic hydrocarbons in a tar cracking process. The results showed that ethylbenzene was converted into lighter gases meaning that the chars were efficient for this. Ethylbenzene conversion at $650{ }^{\circ} \mathrm{C}$ was found to be significantly higher with the char from a mixture of sludge and food waste (c.FW/CFS) compared to that of wood-based char (c.UWP): 71 wt.\% against 45 wt.\%, respectively. The combination of multi-scale and complementary techniques has highlighted that the higher catalytic activity of this char was mainly attributed to the mineral content. Well dispersed mineral particles with various morphologies and natures were observed on the surface of c.FW/CFS using Scanning and Transmission Electron Microscopy (SEM and TEM). Especially, Ca, $\mathrm{Al}$ and $\mathrm{P}$ were the main mineral species identified using XRFS and SEM. These mineral species in form of oxides and hydroxyapatite were considered to be the main active mineral components for tar cracking. Oxides were identified using EDX-analysis. XRD analysis highlighted the presence of crystalised particles of hydroxyapatite $\left(\mathrm{Ca}_{5}\left(\mathrm{PO}_{4}\right)_{3}(\mathrm{OH})\right)$, while Raman spectroscopy revealed that these particles were embedded in the carbon matrix.
\end{abstract}

Keywords:

Catalyst

Pyrolysis

Chars

Mineral species

Multi-scale characterisation

Abbreviations: UWP, used wood pallets; FW, food waste; CFS, coagulationflocculation sludge; c.UWP, char from UWP; c.FW/CFS, char from a mixture of FW (50wt.\%) and CFS (50wt.\%); c.UWP/FW/CFS, char from a mixture of UWP (50wt.\%), FW (25wt.\%) and CFS (25wt.\%); AAEM, alkali and alkaline earth metallic species.

* Corresponding author at: Université de Toulouse, Mines Albi, CNRS, Centre RAPSODEE, Campus Jarlard, Route de Teillet, F.81013 Albi Cedex 09, France.

E-mail address: maxime.hervy@mines-albi.fr (M. Hervy).

\section{Introduction}

To cope with the increase of energy demand, the depletion of fossil fuel resources and the increase of greenhouse gas emissions, the research of alternatives for clean energy production is one of the twenty-first century challenges. Among those alternatives, the energetic valorisation of biomass and waste using pyro- 
gasification is one of the most promising options. Pyro-gasification consists in converting biomass and/or waste into gaseous energy carrier by partial oxidation at high temperature $\left(800-1000{ }^{\circ} \mathrm{C}\right.$ ) with an oxidising agent (air, steam, oxygen or carbon dioxide). Synthetic gas $\left(\mathrm{CO}+\mathrm{H}_{2}\right)$, the main expected product, usually needs to be purified before further utilisation. The elimination of pollutants such as tars, $\mathrm{H}_{2} \mathrm{~S}$, and fine particles in the synthetic gas is one of the main industrial challenges of the pyro-gasification process.

The pyro-gasification process encompasses four steps: drying, pyrolysis, gasification and finally, reforming of the pyrolysis chars and condensable gases. During pyrolysis, biomass is decomposed at moderate temperatures $\left(<700^{\circ} \mathrm{C}\right)$ under reducing atmosphere and solid residues, namely chars, are formed. They represent $15-$ 30 wt.\% of the initial biomass and contain about $25 \%$ of the initial recoverable energy. Chars are carbonaceous materials with a variable part of mineral species depending on the initial biomass. They can be used as fuel in gasification process only if their concentrations of heavy metals and mineral species are low. Above ash contents of $5 \%$, clinkering and slagging problems occur due to the fact that the gasification temperature is often higher than the melting point of the biomass ash [1]. Moreover, chars with high mineral and metal content have low energy potential and their gasification leads to the production of a heavily polluted syngas. Otherwise, chars can be used in higher added-value applications than if used for energy, such as environmental remediation (removal of pollutants in air or wastewater) and catalysis (as catalysts or catalyst supports). As an example, pyrolysis chars with or without modification are already known to be efficient sorbent or catalyst for gas cleaning $[2,3]$. This byproduct of thermochemical process is also relatively inexpensive compared to other synthetic catalysts used in tar cracking processes [4]. Due to important differences in the structure and mineral content of the initial feedstock, the resulting chars can display significant variations in physical and chemical properties [4]. Moreover, the pyrolysis process conditions strongly influence the properties of the resultant char [5]. The catalytic activity of pyrolysis chars is mainly determined by four characteristics: (a) the disorganized and porous structures [6,7]; (b) the presence of O-containing groups on the char surface $[8,9]$; (c) the structure of the carbonaceous matrix [10,11]; (d) active sites formed by the alkaline ( $\mathrm{Na}, \mathrm{K}$ ) and alkaline earth $(\mathrm{Mg}, \mathrm{Ca})$ species distributed in the char matrix $[7,12,13]$.

The influence of each above mentioned property on the catalytic activity of chars for tar cracking reactions, as well as their combined effects, still remains unclear. A recent study showed that if the tar cracking temperature is higher than the temperature of char production, secondary pyrolysis can occur, resulting in textural properties and carbonaceous structure changes affecting the char activity [7]. Nevertheless, the presence of mineral species has been identified to be of prime importance in the char catalytic activity [8]. Recently, the use of chars as catalysts or catalyst supports in tar cracking reactions has been intensively studied $[3,4,6]$. However the main studies only concerned the characterisation of the mineral content at the bulk scale. The analysis of mineral content without any details on its distribution and speciation is not sufficient to understand how efficient the catalytic activity of minerals in the char could be. Many parameters (such as speciation, size of crystallites and spatial distribution) could influence this catalytic activity. The speciation and amount of mineral species should be investigated to identify the presence of active and inhibitory species. The size of minerals and their spatial distribution are decisive in the catalytic and inhibitory phenomena. Indeed, small and well-dispersed mineral species on the char surface provide many active sites that promote the catalytic activity of char and reduce the deactivation by coke deposition [14]. In addition, the carbonaceous matrix has been demonstrated to be important feature, as small aromatic rings in carbon structure and defects in graphene like sheets promote the char reactivity $[7,12,15]$.

The aim of this paper is to study the content, the speciation and the distribution of mineral species of pyrolysis chars to better understand the mineral structure of such complex matrix and its catalytic role in tar cracking reactions. Three chars with various mineral contents were produced from three different feedstocks produced on cruise ships. Emphasis was placed on a set of complementary characterisation techniques performed at different scales: bulk, surface (studied at micro and nano-scale) and crystallite scale. The distribution and size of minerals were investigated by SEM and TEM while their speciation and crystallinity were studied by XRFS and XRD. Moreover, original data related to the interactions between the mineral species and the char matrix has been provided by the Raman spectroscopy. This technique was used to characterise the composition, the distribution, the structure of the carbonaceous and the mineral species on the surface and within the char. Finally, the two chars with the most different compositions were used as catalysts in a tar cracking process in order to assess the influence of the mineral species on tar cracking efficiency. These data lead to a complete description of the mineral species in the char and a better understanding of the relationships between minerals and the catalytic activity of chars.

\section{Materials and methods}

\subsection{Raw materials}

The materials used in this study were Used Wood Pallets (UWP), Food Waste (FW) and Coagulation-Flocculation Sludge (CFS), all of them were wastes coming from cruise ships. The interests of studying these wastes lie in their very different mineral content and in their large availability. UWP was common softwood (from gymnosperm trees) used in the production of pallets for loading and transportation of food. Food wastes came from feeding activity, and were composed of a mixture of vegetables and animal wastes. Coagulation-Flocculation Sludge was recovered from a wastewater treatment plant present on board the ship. FW and CFS were partially dehydrated in a screw press up to a moisture content of $80 \mathrm{wt} . \%$ and dried up to a moisture of $30 \mathrm{wt} . \%$ in a steam dryer (Scanship). Before pyrolysis, these wastes were stored in closed bags. UWP was chipped in particles of average diameter of $3 \mathrm{~cm}$ and stored indoors.

\subsection{Pyrolysis treatment}

The chars were produced in a semi-continuous horizontal screw reactor (internal diameter of $0.167 \mathrm{~m}$ and $2 \mathrm{~m}$ in length). The pyrolysis was performed at $700{ }^{\circ} \mathrm{C}$ during $30 \mathrm{~min}$ with a heating rate of $22{ }^{\circ} \mathrm{C} \cdot \mathrm{min}^{-1}$. A slow pyrolysis was chosen in order to maximise the char yield and reduce the volatilisation of mineral species. The details of the experimental procedure were described in a previous paper [16]. From such a treatment, three different pyrolysis chars were produced: (1) c.UWP, only from UWP, (2) c.FW/CFS, from a mixture of $50 \mathrm{wt} . \% \mathrm{FW}$ and $50 \mathrm{wt} . \% \mathrm{CFS}$, and (3) c.UWP/FW/ CFS, from 50 wt.\% UWP, 25 wt.\% FW and 25 wt.\% CFS. The mixtures of the feedstocks were hand-made. The flow rate of feedstocks was $8.9 \mathrm{~kg} / \mathrm{h}$ for c.UWP and c.FW/CFS, and $7.1 \mathrm{~kg} / \mathrm{h}$ for c.UWP/FW/CFS. In these conditions, the char yields were $22 \mathrm{wt} . \%$ for c.UWP and c. UWP/FW/CFS, and $23 \mathrm{wt} . \%$ for c.FW/CFS. The char yields are in agreement with the literature results of wood chars produced in similar conditions [6]. These waste mixtures allowed producing three chars with various mineral contents, since CFS and FW contained more mineral compounds than UWP. Chars were sieved to particle size from 0.5 to $1.6 \mathrm{~mm}$. This size fraction represented 
29 wt.\% of c.UWP, 18 wt.\% of c.FW/CFS and 22 wt.\% of c.UWP/FW/ CFS. Prior to analyses, the chars were mixed in order to homogenise the samples.

\subsection{Characterisation of raw materials and pyrolysis chars}

\subsubsection{Elemental analysis}

Prior to elemental analyses, the moisture of samples was eliminated at $105^{\circ} \mathrm{C}$ while measuring the mass evolution until stabilisation. The elemental composition $(\mathrm{C}, \mathrm{H}, \mathrm{N}, \mathrm{S})$ of the samples was determined by using a Thermo Finnigan AE1112 Series Flash and was performed following the French standard NF-M03-002. The detection limit of this apparatus was $0.2 \mathrm{wt} . \%$. The ash content of the parent feedstocks and chars was determined by measuring the residual mass after the combustion of $7.0 \mathrm{~g}$ of the sample for $15 \mathrm{~h}$ in a muffle furnace (Nabertherm P330) at a temperature of $550^{\circ} \mathrm{C}$ and $650^{\circ} \mathrm{C}$, respectively. The oxygen content was calculated by difference. For the above mentioned characterisations, at least three samples of each material were analysed and the average values are presented in the results. The variation between each measurement never exceeded $10 \%$ of the average value.

\subsubsection{X-ray fluorescence spectroscopy (XRFS)}

The chemical composition at the overall scale of resulting ash was analysed by X-ray fluorescence spectroscopy (SHIMADZU EDX-800HS). The analyses were performed under vacuum with powdered samples, with a time acquisition of $100 \mathrm{~s}$ and a detection limit of $0.001 \mathrm{wt} . \%$. The ash was obtained from the combustion of around $20 \mathrm{~g}$ of each material. Thus, large samples representative of the materials were analysed which allowed to deal with the chemical heterogeneity of the waste. First analyses showed no significant differences between the composition of the main mineral species in the material prior to combustion and in the ash after combustion. The concentration of the mineral species being higher in ash than in the raw materials, more species were detected by XRFS analysis. Thus, the XRFS analyses were performed on the ash.

\subsubsection{Raman spectroscopy}

Raman spectroscopy was used to determine the different carbon structure of the chars as well as to study the structure and composition of minerals on the surface and within the chars. Raman spectra were acquired for each sample at room temperature and in air using a Confocal Raman - AFM WITEC Alpha 300AR microscope equipped with a CCD camera detector. Spectra were recorded using a lens $50 \times(\mathrm{Na}=0.75)$ and an excitation laser at $532 \mathrm{~nm}$ in the region of $175-4000 \mathrm{~cm}^{-1}$ of Raman shift. Confocal microscopy was used to insure the focalisation of Raman laser at the surface or in depth of the sample. For each char, at least two zones of a particle were analysed. The analyses were performed at the particle surface (on a square of $5 \mu \mathrm{m}$ ), and in the bulk (at a depth of $3 \mu \mathrm{m}$ ). All the spectra collected in the different regions were then post-treated to obtain an average spectrum of the sample in each zone studied. In hybrid materials composed of a carbonaceous matrix and minerals, the post treatment was applied to the spectra to discriminate both contributions. The spectra were compared with those of the RRUFF database [17] in order to identify the mineral species.

Raman spectroscopy is based on the interaction between a laser and the matter which leads to an excitation of the molecule skeleton. The Raman spectrum reflects the response of the sample to this excitation and the bands are attributed to vibration modes of the carbon structures and mineral species in the sample. Therefore this technique was used to compare the ratio of each carbon structure in the samples using deconvolution post-treatment. Basically Raman spectrum of carbonaceous solids was composed of two main broad bands at the first order: the $G$ band at $1585 \mathrm{~cm}^{-1}$ and the $\mathrm{D}$ band at $1350 \mathrm{~cm}^{-1}$ referring to the graphene sheets and graphene-like sheets, and to the large aromatic systems and defects in graphene-like sheets, respectively [17]. According to the literature $[10,18]$, the overall spectrum can be separated in ten peaks and the assignments are summarized in Table A.1. Therefore the curve-fitting of Raman spectra in ten Gaussian peaks was performed in the $800-1800 \mathrm{~cm}^{-1}$ range of frequencies with the Matlab ${ }^{\circledR}$ software. The band position and a constraint over the band width were used for this study. Four ratios based on the relative surface area of the peaks should be defined in order to characterise the carbonaceous structure (Table 1) $[18,19]$.

\subsubsection{X-ray powder diffraction (XRPD)}

X-ray powder diffraction (XRPD) analyses were carried out at room temperature using a Philips Panalytical X'pert Pro MPD diffractometer equipped with a X'celerator linear detector (127 detectors). XRPD patterns were collected with a $\mathrm{Cu} \mathrm{K} \alpha$ radiation source $(1.541 \AA$ ) operating at $45 \mathrm{kV}$ and $40 \mathrm{~mA}$. The whole diffraction pattern was collected between $2 \theta=9^{\circ}$ and $2 \theta=75^{\circ}$ with a step size of $0.033^{\circ}$ in $2 \theta$ and an integration time of about 200 s per step leading to a total acquisition time of $52 \mathrm{~min}$ for every sample. A silica standard sample was used to calibrate the diffractometer. The phase identification was performed using the JCPDS database.

\subsubsection{Scanning electron microscopy-energy dispersive X-ray analyses (SEM-EDX)}

The chars were characterised by scanning electron microscopy (SEM) using a ZEISS DSM982 microscope equipped with a high resolution Gemini column, operated at $10-15 \mathrm{kV}$. Prior to observation, samples were coated with a 2-3 nm Au/Pd layer to ensure electrical conductivity. The local chemical composition at micro-scale was assessed by energy dispersive X-ray spectroscopy (EDX) using a Noran Voyager IV microanalysis system. For each char, several zones were analysed in order to obtain a statistical dataset representative of the materials.

\subsubsection{Transmission electron microscopy (TEM) observation and STEM- EDX analyses}

Transmission electron microscopy (TEM) and scanning transmission electron microscopy (STEM) combined with energy dispersive X-ray spectroscopy (EDX) analyses were used to locally characterise the chemical composition of chars at the nanometric scale. TEM samples were prepared by ultramicrotomy using a LEICA Ultracut R Ultramicrotome. Char fragments of approximately 2-3 $\mathrm{mm}^{3}$ were inserted into standard BEEM capsules (Agar Scientific) and embedded in an epoxy resin in order to produce blocks with a pyramidal top well-suited for cutting operation. The resin polymerisation was carried out at $55^{\circ} \mathrm{C}$ for $4 \mathrm{~h}$. Such a resin is well-known to provide appropriate results in terms of cutting quality for carbon-graphite materials [20]. After being removed from the mould, the block top was perfectly flatten using a diamond trimming tool $45^{\circ}$ (DiATOME). Thin slices of $\sim 100 \mathrm{~nm}$ thick were then cut using a $35^{\circ}$ ultra diamond knife (DiATOME) with a cutting speed of $1 \mathrm{~mm} / \mathrm{s}$ and a clearance angle of $6^{\circ}$. The undamaged rectangular sections floating on the surface of the water bath were gently collected with a perfect loop and transferred onto 300 square mesh gold grids (Agar Scientific). TEM characterisation was performed using a FEI Tecnai F20 ST TEM, operated at $200 \mathrm{kV}$ and equipped with a field emission gun (FEG) electron source. High angle annular dark field (HAADF) images were acquired in scanning STEM mode using a Model 3000 Annular Dark Field detector (Fishbone Instruments). EDX measurements were recorded using a Sapphire $\mathrm{Si}(\mathrm{Li})$ detector (EDAX). 
Table 1

Ratios definition for the interpretation of Raman spectra.

\begin{tabular}{ll}
\hline Ratio & Description \\
\hline $\mathrm{I}_{\mathrm{G}} / \mathrm{I}_{\text {tot }}$ & Graphene sheets and graphene-like sheets \\
$\mathrm{I}_{\mathrm{D}} / \mathrm{I}_{\text {tot }}$ & Large aromatic rings systems $(\geqslant 6$ rings $)$ and \\
$\left(\mathrm{I}_{\mathrm{Gr}}+\mathrm{I}_{\mathrm{Vl}}+\mathrm{I}_{\mathrm{Vr}}\right) / \mathrm{I}_{\text {tot }}$ & imperfections in graphene-like sheets \\
$\mathrm{I}_{\mathrm{S}} / \mathrm{I}_{\text {tot }}$ & Small aromatic rings systems (3-5 rings) \\
\hline
\end{tabular}

\section{Results and discussion}

\subsection{Overall composition of parent feedstocks}

Table 2 summarises the ultimate composition of materials. Compared to most of sludge, CFS presented relatively low ash content (17.5 wt.\%), similar to sludge from a wastewater treatment scheme including aerobic biological treatments with low aeration time [21]. The relatively high carbon content of the sludge (39.9 wt.\%) can result from the low oxidation of the biodegradable matter. The elemental composition of FW was close to that of CFS, and only differed in lower ash content (11.9 wt.\%) and higher oxygen content ( $34.0 \mathrm{wt} . \%$ against $30.5 \mathrm{wt}$.\% for CFS). UWP presents an elemental composition comparable with that of pine wood in terms of major elements [22].

Significant differences can be observed in the composition of the feedstocks ashes. The global ash compositions measured with $\mathrm{X}$-ray fluorescence spectrometry are presented in Table 3. Calcium was the main inorganic specie of UWP and FW ashes (41.0 and 46.9 wt.\% respectively) while it only represented 17.9 wt.\% in CFS ash. FW and CFS ashes were rich in phosphorus (16.4 and 27.2 wt.\% respectively). FW ashes were characterised by high chloride content (16.0 wt.\%) while CFS ashes contained high aluminium content (42.4 wt.\%). The presence of aluminium in CFS resulted from the use of aluminium salts as flocculation agent in the wastewater treatment process. The ashes composition of UWP and CFS are typical of that found in the literature [21,23].

\subsection{Chemical composition of chars}

This section details the successive characterisations carried out on the chars at different scales. First, the chemical composition of chars was investigated with a main focus on the mineral species. Then, the carbonaceous structure was analysed in order to study the relationships between the mineral species and the char matrix. These characterisations were performed at the bulk scale, at the crystallite scale and at the surface scale (micro and nano-scale observations) in order to reach an accurate description of the mineral species. Finally, the catalytic activity of these low-cost and eco-friendly materials was studied and analysed in relation with the state-of-the-art and physico-chemical properties determined in this work.

\subsubsection{Proximate and ultimate analyses}

Table 2 reports the elemental composition of the chars used in this study. Whatever the type of raw materials pyrolysed, the carbon mainly remained in the solid matrix which became more aromatic. During the pyrolysis, the carbon content increased by $81 \%$ for both UWP-based materials and only $9 \%$ in the FW/CFS-based char. At the same time, hydrogen and oxygen contents decreased respectively by $75 \%$ and $80 \%$ for all materials. These results are in agreement with the literature dealing with slow pyrolysis and are explained by the breaking of the weakest chemical bonds in the structure of the chars $[11,24]$. The wood char (c.UWP) was characterised by a low ash rate and high carbon content ( 2.1 and
87.2 wt.\%, respectively). The char produced from FW and CFS (c. FW/CFS) consisted of an organic/inorganic hybrid material containing a large amount of ash and low carbon content (47.0 and $44.1 \mathrm{wt} . \%$, respectively). The third char c.UWP/FW/CFS can be seen as an intermediate material. Although its carbon content was still high (80.2 wt.\%), the ash amount was close to $10 \mathrm{wt}$.\% which was lower than the expected value based on the initial mixture of feedstocks (theoretical value equals $25 \mathrm{wt} . \%$ ). An interaction between the two feedstocks might occur during the pyrolysis leading to a lower conversion of organics from UWP feedstock and higher ash volatilisation, as mentioned in the literature [25,26]. Therefore the mineral content and its distribution were particularly discussed for both mineral chars (c.FW/CFS and c.UWP/FW/CFS).

\subsubsection{Mineral composition}

Three mineral species represented between 58 and $72 \mathrm{wt} . \%$ of the inorganic matter of the whole chars: calcium, potassium and phosphorus (Table 3). Calcium was the main alkaline earth mineral specie present in the three feedstocks, and was mainly concentrated in the chars after pyrolysis. These results confirmed that non monovalent species are less easily released during slow pyrolysis than monovalent species $(\mathrm{Na}, \mathrm{K})[3,27,28]$. The concentration of phosphorus was significantly higher in c.FW/CFS and c.UWP/ FW/CFS than in FW/CFS and UWP/FW/CFS (raw mixtures). This was confirmed by thermodynamic calculations which showed that phosphorus was present only in the form of calcium phosphate $\left(\mathrm{Ca}_{3}\left(\mathrm{PO}_{4}\right)_{2}\right)$ and the concentration increases with increasing temperature $\left(500-700^{\circ} \mathrm{C}\right)$ (Supplementary information). On the contrary, the amount of potassium in ashes decreased significantly as this element vaporises easily under the pyrolysis conditions used [27-29]. Aluminium content (from CFS) was surprisingly higher in c.UWP/FW/CFS than in c.FW/CFS. The most likely explanation is the high heterogeneity of this char produced from a mixture of three feedstocks. This heterogeneity could come from the step of manual mixing of feedstocks and from an inhomogeneous flow in the screw reactor. The difference of density of the three feedstocks could have led to a heterogeneous mixture. While chlorine is known to vaporise as alkali chlorides at pyrolysis temperature higher than $600{ }^{\circ} \mathrm{C}[30]$, it seems in the present case to be partially retained into the char matrix. Chlorine (from FW) was detected in c.FW/CFS and c.UWP/FW/CFS ( 7.5 and 3.7 wt.\%, respectively). This phenomenon could be explained by the high calcium content. Indeed, calcium oxide has a "stabilising" effect on $\mathrm{Cl}$ that delays or even prevents its volatilisation [31]. In addition, $\mathrm{Cl}$ can combine with free radical sites formed during the pyrolysis by the massive breaking of chemical bonds at high temperature, leading to an extended retention of $\mathrm{Cl}$ in the char [32]. Some phosphates, such as $\mathrm{CaP}$, have also been found to stabilise metals, and could prevent their volatilisation during thermal treatments [33]. Thermodynamic calculations confirmed that $\mathrm{Cl}$ is present in the c.FW/CFS ash mainly as $\mathrm{KCl}$ (8.2 wt.\%) and $\mathrm{CaCl}_{2}$ (4.6 wt.\%) (Supplementary information). Magnesium, initially present in the wood composition, was mainly recovered in c.UWP. Silicon content was originally low in the feedstocks and was not significantly modified during pyrolysis. At high temperature, the presence of silicon in the char could lead to the formation of alkali silicates which inhibit the catalytic effect of alkali and alkaline earth metallic (AAEM) species in tar cracking reactions $[25,34]$. In this study, the inhibitory effect of silicon would be negligible due to its low concentration in chars. Other studies highlighted the trend of phosphorus to encapsulate potassium during thermal process, thus inhibiting its catalytic effect [35]. Hence, the speciation of mineral species as well as the morphology and distribution of mineral particles have been analysed to understand the catalytic activity of these materials. 
Table 2

Ultimate analysis of the materials.

\begin{tabular}{|c|c|c|c|c|c|c|}
\hline Material & C (wt.\%) & $\mathrm{H}(\mathrm{wt} . \%)$ & $\mathrm{N}$ (wt.\%) & O (wt.\%) (by difference) & Ash (wt.\%) & Moisture (wt.\%) \\
\hline UWP & 48.2 & 6.5 & n.d. & 44.6 & 0.7 & 10.1 \\
\hline FW & 40.9 & 5.8 & 7.4 & 34.0 & 11.9 & 9.4 \\
\hline CFS & 39.9 & 5.4 & 6.7 & 30.5 & 17.5 & 18.3 \\
\hline c.UWP & 87.2 & 1.8 & 0.6 & 8.3 & 2.1 & 1 \\
\hline c.FW/CFS & 44.1 & 1.3 & 3.1 & 4.5 & 47.0 & l \\
\hline c.UWP/CFS/FW & 80.2 & 1.4 & 1.2 & 7.7 & 9.5 & l \\
\hline
\end{tabular}

n.d.: non detectable.

Table 3

Ash composition of feedstocks and chars measured with XRF.

\begin{tabular}{|c|c|c|c|c|c|c|}
\hline Inorganic elements (dry wt.\%) & UWP & FW & CFS & c.UWP & c.FW/CFS & c.UWP/FW/CFS \\
\hline $\mathrm{CaO}$ & 41.0 & 46.9 & 17.9 & 42.5 & 39.2 & 32.3 \\
\hline $\mathrm{P}_{2} \mathrm{O}_{5}$ & 4.8 & 16.4 & 27.2 & 4.7 & 26.2 & 21.5 \\
\hline $\mathrm{K}_{2} \mathrm{O}$ & 18.5 & 13.1 & 4.5 & 11.0 & 6.4 & 7.2 \\
\hline $\mathrm{Al}_{2} \mathrm{O}_{3}$ & 3.4 & bdl & 42.4 & 3.0 & 13.8 & 21.0 \\
\hline $\mathrm{Cl}$ & bdl & 16.0 & 0.6 & bdl & 7.5 & 3.7 \\
\hline $\mathrm{Fe}_{2} \mathrm{O}_{3}$ & 4.0 & 0.3 & 0.9 & 6.5 & 1.6 & 1.3 \\
\hline $\mathrm{SO}_{3}$ & 8.4 & 3.6 & 2.7 & 6.6 & 2.7 & 4.5 \\
\hline $\mathrm{SiO}_{2}$ & 5.5 & 0.6 & 3.5 & 8.0 & 2.0 & 4.0 \\
\hline $\mathrm{MgO}$ & 8.5 & 2.8 & bdl & 11.0 & bdl & 3.0 \\
\hline Others $\left(\mathrm{TiO}_{2}, \mathrm{MnO}, \mathrm{ZnO}, \mathrm{CuO}, \mathrm{SrO}\right.$, etc.) & 5.9 & 0.3 & 0.3 & 6.7 & 0.6 & 1.5 \\
\hline
\end{tabular}

bdl: below the detection limit; traces: $<0.001 \mathrm{wt} . \%$.

\subsubsection{Characteristics of mineral species}

The dispersion and the size of mineral particles on the char surface play an important role in tar cracking reactions. Indeed, small and well-dispersed mineral species on the char surface provide many active sites that promote the catalytic activity of char. The morphology of char particles and the distribution of mineral species were observed at micro-scale by SEM. STEM-EDX characterisation was carried out on the samples at higher magnification in order to investigate the distribution and the composition of mineral particles in the bulk at nano-scale. As the structure defects produced by the presence of crystals could be responsible for char reactivity, this parameter is of primary importance to characterise catalysts. Thus, to assess the presence of crystalline phases, XRD measurements were performed. Since active sites on the surface can be deactivated by coke deposit, it is important to know if the minerals are either included in the char matrix or deposited on its surface. In-depth Raman analyses were achieved to tackle this issue.

3.2.3.1. Surface mapping at micro- and nano-scale. SEM characterisation revealed the presence of particles on the surface of the three chars, the dimension of which was below $2 \mu \mathrm{m}$ (Fig. 1). For c.UWP, although some regions showed a fairly smooth surface (Fig. 1A), most of the sample exhibited a rough surface with outcropping particles (Fig. 1B and C). The macrostructure of c.UWP was typical of wood chars and consisted of a network of hollow fibers resembling honeycomb-like structures [3]. However, for some particles of c.UWP, deformation or even destruction of this macrostructure was observed, as for UWP (Supplementary information). This could be explained by the fact that UWP was compressed during the pallet manufacturing process. Back scattered electron (BSE) imaging indicated a difference in chemical composition between the matrix and these particles. Further investigation using EDX on different zones of the sample showed that the c.UWP matrix locally contained particles of $\mathrm{Ti}, \mathrm{Fe}, \mathrm{Si}, \mathrm{Na}, \mathrm{Mg}, \mathrm{S}$, Ca elements, and traces of $\mathrm{Al}$ and $\mathrm{K}$. Thus, these local analyses enabled to conclude that the chemical composition was not uniform at the scale of the sample. STEM-EDX measurements were performed at higher magnification in order to study at nano-scale the local chemical composition of the char matrix. Measurements performed on several zones of the sample randomly chosen indicated a homogeneous composition of c.UWP matrix dominated by the $\mathrm{C}$ and $\mathrm{O}$ elements, with traces of $\mathrm{Si}, \mathrm{Ca}, \mathrm{Na}$ and $\mathrm{Mg}$. In addition, c.UWP exhibited a homogeneous and dense microstructure without any crystallised particles, as shown by TEM observation (Fig. 2A). The corresponding selected area for the electron diffraction (SAED) pattern displaying diffuse rings was typical of an isotropic, short-range ordered material. HAADF imaging revealed no significant chemical contrast. These results suggested the absence of crystallised mineral particles in the bulk of c.UWP.

For c.FW/CFS, particles embedded in the matrix were easily observed (Fig. 1E). The C, O, Na, Mg, Al, Si, P, Cl, K and Ca elements were systematically detected by EDX in the different probed zones. This char showed a variety of particle morphologies, among them round, square, or worm-like particles but also fibrils were observed (Fig. 1F and G). Similar shape heterogeneity was observed for chars from different sludge in the literature [21]. Some of the particles were chemically different from the matrix as revealed by BSE imaging (Fig. $1 \mathrm{H}$ ). For instance, oxides of $\mathrm{Si}$, or $\mathrm{Cl}, \mathrm{K}$ and $\mathrm{Na}$, or $\mathrm{Fe}$, or $\mathrm{Ca}, \mathrm{P}$ and $\mathrm{Al}$ elements were identified by EDX measurements.

Crystallised particles having various shapes and sizes were observed at nano-scale in c.FW/CFS matrix by TEM. An example is displayed in Fig. 2B, but many other particle morphologies and distribution were revealed. The inter-planar spacings measured on the SAED patterns could be assigned to various mineral oxides. HAADF imaging as well as STEM-EDX measurements on different zones of the sample indicated that the chemical composition of $c$. FW/CFS matrix was homogeneous. The matrix was formed by a carbonaceous material with high content of $\mathrm{Al}, \mathrm{Ca}$ and $\mathrm{P}$ oxides. Traces of other elements such as $\mathrm{Si}, \mathrm{Na}, \mathrm{Cl}$ or $\mathrm{Mg}$ were also detected. The results of STEM-EDX are in agreement with those from the SEM-EDX characterisation and corroborate the overall composition quantified by elemental analysis and XRFS.

The c.UWP/FW/CFS char exhibited a macrostructure similar to that of c.UWP (Fig. 1I) and showed a rough surface, with particles similar to those revealed in c.FW/CFS (Fig. $1 \mathrm{~J}$ and $\mathrm{H}$ ). The matrix composition was close to that of c.UWP and consisted mostly of $\mathrm{C}, \mathrm{O}$ elements with traces of $\mathrm{Na}, \mathrm{Mg}, \mathrm{Al}, \mathrm{Si}, \mathrm{S}, \mathrm{Cl}, \mathrm{K}, \mathrm{Ca}$ and $\mathrm{Ti}$. EDX analyses revealed that the particles were composed of $\mathrm{Ca}, \mathrm{P}$, $\mathrm{Al}$ and $\mathrm{Si}$ oxides. No crystallised particles were observed by TEM 

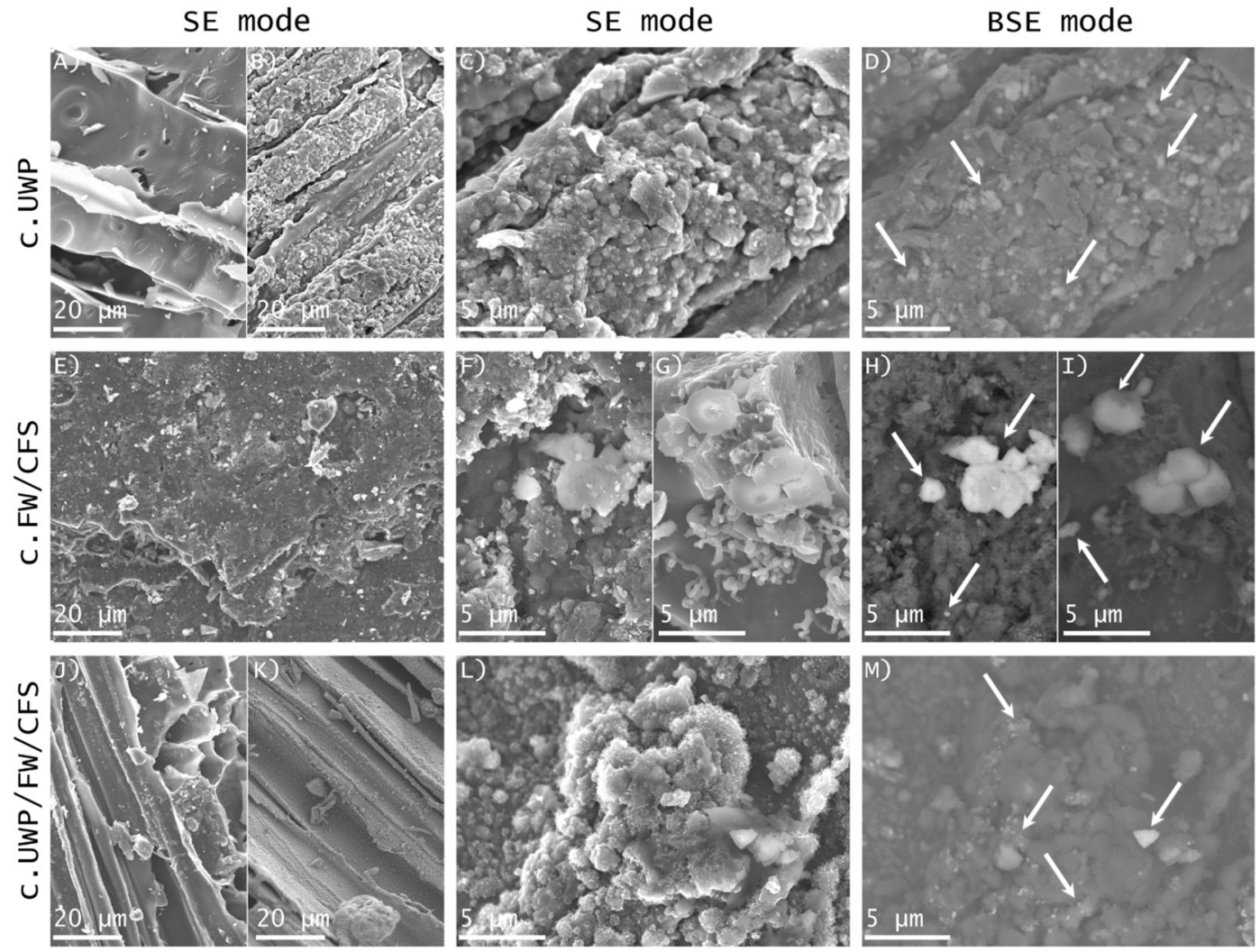

Fig. 1. Scanning electron micrographs acquired in secondary electron (SE) mode (topological contrast) and backscattered electron (BSE) mode (chemical contrast) of samples c.UWP (A, B, C and D), c.FW/CFS (E, F, G, H and I), and c.UWP/FW/CFS (J, K, L and M). For each material, regions viewed using successively the SE and BSE modes are shown in the middle and right columns respectively. In BSE mode, mineral particles appear brighter than the matrix. Some of them are marked with an arrow.

for c.UWP/FW/CFS. STEM-EDX results revealed that the matrix composition was similar to that of c.UWP, although some nodes high in Si or Ca could be locally detected. Thus, SEM and TEM characterisations showed that c.UWP/FW/CFS - produced from the mixture of UWP and FW/CFS - exhibited features observed for chars produced separately from UWP and FW/CFS. No crystalline species were observed in c.UWP, on the contrary to c.FW/CFS and c.UWP/FW/CFS. Then, both chars were characterised in the next section to go further with crystalline species.

3.2.3.2. Crystallinity of minerals. To investigate the crystallinity of the mineral particles observed with SEM, XRD patterns of samples were recorded. As this analysis was carried out on a large powdered sample, the data obtained are relevant at the bulk scale. According to Tables 2 and 3 , the concentrations of $\mathrm{Ca}, \mathrm{P}, \mathrm{K}, \mathrm{Al}, \mathrm{Cl}$ and $\mathrm{S}$ elements were detectable in c.UWP/FW/CFS and c.FW/CFS by XRD. The patterns of c.FW/CFS and c.UWP/FW/CFS are presented in Fig. 3. The pattern of c.FW/CFS presented many peaks which could be attributed to the hydroxyapatite $\left(\mathrm{Ca}_{5}\left(\mathrm{PO}_{4}\right)_{3}(\mathrm{OH})\right)$ phase. For c.UWP/FW/CFS, two crystalline minerals were identified: hydroxyapatite $\mathrm{Ca}_{5}\left(\mathrm{PO}_{4}\right)_{3}(\mathrm{OH})$ and alumina $\left(\mathrm{Al}_{2} \mathrm{O}_{3}\right)$. However, the response of the amorphous carbon was predominant (width diffraction peaks in the regions of 2.4 and $5 \AA$ ).

Hydroxyapatite $\mathrm{Ca}_{5}\left(\mathrm{PO}_{4}\right)_{3}(\mathrm{OH})$ was the main crystalline phase detected by XRPD analysis in both c.FW/CFS and c.UWP/FW/CFS. The presence of this phase - mainly composed of $\mathrm{Ca}$ and $\mathrm{P}$ - in a significant amount is in agreement with the results obtained by XRF spectroscopy. Based on the XRF results, the [Ca]:[P] molar ratios in c.FW/CFS and c.UWP/FW/CFS were calculated. For both chars, the value was around 1.9 which is much higher than that of the stoichiometric hydroxyapatite (1.67). So, other calciumbased compounds (such as $\mathrm{CaCl}_{2}$, and $\mathrm{CaO}$ ) must be present in both chars. Similar results were obtained for sludge-based chars in the literature, where crystallised calcium phosphates particles (brushite) were present together with calcium oxides [21].

3.2.3.3. Interactions between the mineral species and the char matrix. SEM and XRPD characterisations offered a good understanding of the distribution of mineral species on the char surface. However, these two techniques did not allow to determine whether hydroxyapatite and other minerals were only deposited on the surface or included in the char matrix. To investigate this feature, Raman spectroscopy analyses were performed. This technique allowed studying the chemical composition on the char surface (on a square of $5 \mu \mathrm{m}$ ) but also within the char (depth of $3 \mu \mathrm{m}$ ). These data are expected to increase the understanding of the interactions between the mineral species and char matrix.

The post treatment was applied to the Raman spectra in view to separate the mineral and the carbonaceous contributions. For example, Fig. 4 shows the shape of the c.FW/CFS spectra obtained in-depth, as well as their distribution in-depth (Fig. 4B) and at the surface (Fig. 4C). The red ${ }^{1}$ spectra and the red surfaces correspond to the mineral content while the blue ones are referring to a mixture of mineral and carbon contributions. Fig. 5A compares the spectra of the mineral contribution recorded on c.FW/CFS and on a piece of FW/CFS selected from c.UWP/FW/CFS. Three main peaks were observed for each material. Although the surface of these chars was characterised on different zones, this shape-like spectrum was systematically obtained. Fig. 5A also presents the superimposition of the experimental Raman spectra and reference spectra of hydroxyapatite $\left(\mathrm{Ca}_{5}\left(\mathrm{PO}_{4}\right)_{3}(\mathrm{OH})\right)$. This reference spectra was the most suitable to represent the mineral content, as the identification was based on the most intense band. Thus, the Raman analyses con-

${ }^{1}$ For interpretation of color in Fig. 4, the reader is referred to the web version of this article. 

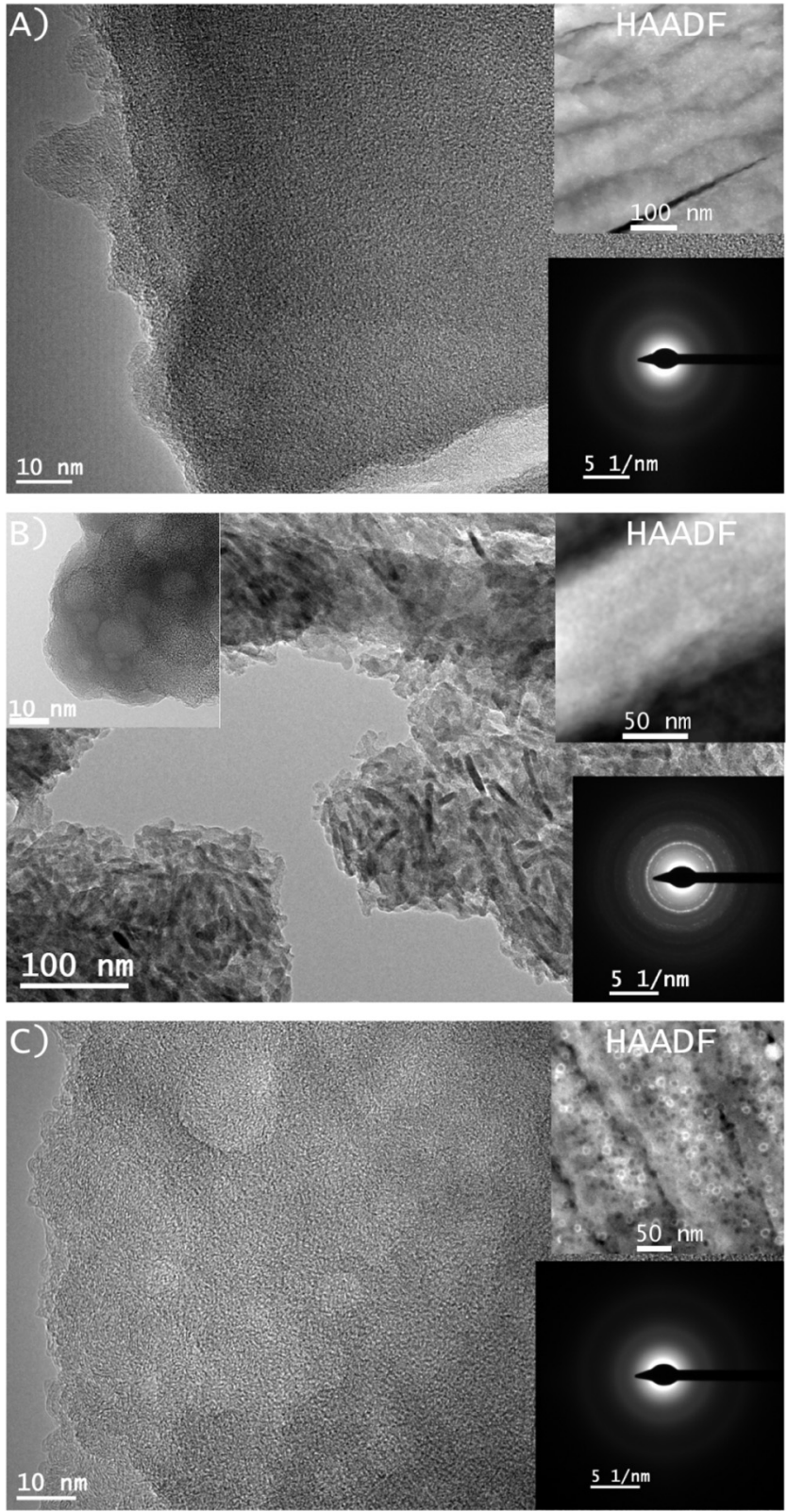

Fig. 2. TEM and STEM-EDX characterisation of samples c.UWP (A), c.FW/CFS, and c. UWP/FW/CFS. The bright field micrographs are accompanied by their corresponding SAED pattern (bottom right), as well as by a HAADF image of the samples (top right).

firmed the presence of hydroxyapatite, already identified with the XRPD patterns. Moreover, depth-profile analyses were performed with the Raman spectroscopy. Similar chemical compositions were obtained on the surface and within the particles of c.FW/CFS and c. $\mathrm{UWP} / \mathrm{FW} / \mathrm{CFS}$. One can conclude that minerals are embedded in the char matrix and not only deposited on the first surface layer.

In conclusion, the different techniques used in this study proved their complementarity in the understanding of the composition of mineral species in the chars. The chemical heterogeneity of the char surface at micro-scale was revealed by SEM, with the presence of mineral particles on the char matrix. The presence of crystallised particles at nano-scale in the matrix of FW/CFS based chars was highlighted by TEM. These crystallised particles were identified as hydroxyapatite by XRPD analyses. Raman spectroscopy specified that hydroxyapatite particles were embedded in the char matrix and not deposited on the surface. The hexagonal structure of

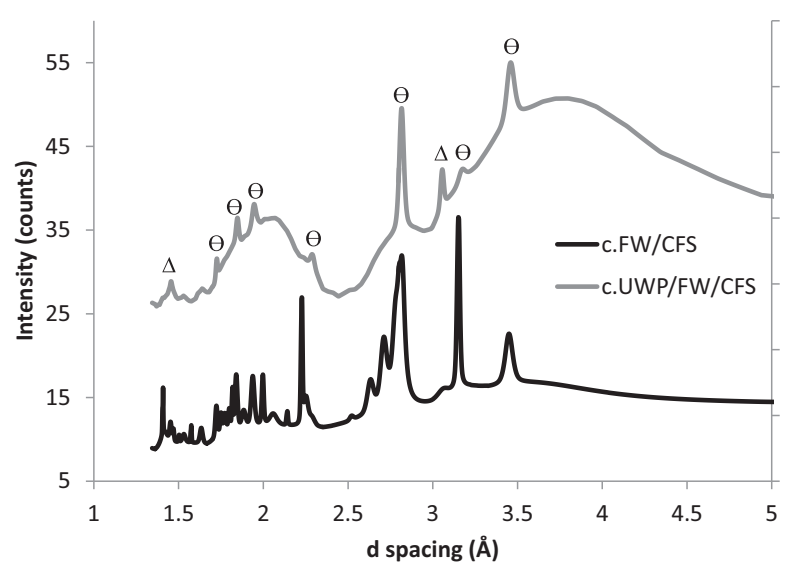

Fig. 3. XRPD patterns of $\mathrm{c.FW} / \mathrm{CFS}$ and c.UWP/FW/CFS ( $\Delta$ corresponds to alumina peaks; $\theta$ corresponds to the main peaks of hydroxyapatite).

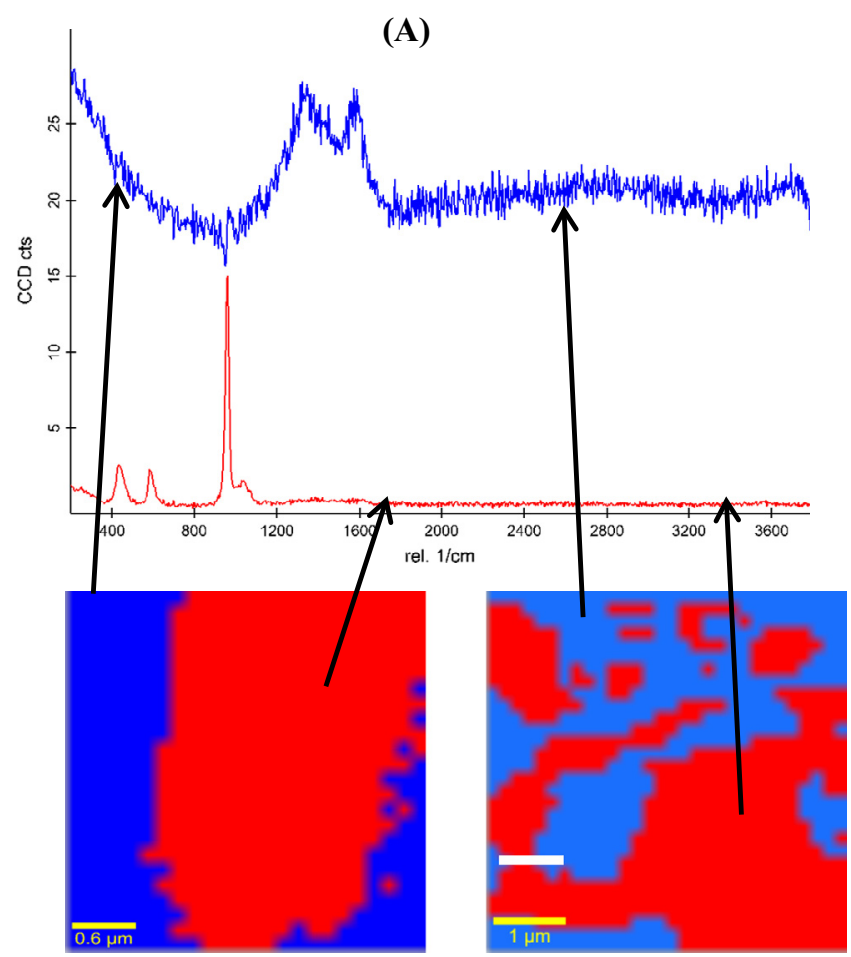

(B)

(C)

Fig. 4. (A) Raman spectra obtained in-depth of the c.FW/CFS sample (blank line in Fig. 4C); (B) these spectra distribution in-depth; (C) spectra distribution obtained on the surface on the sample.

hydroxyapatite could explain its easy insertion in the hexagonal system of the graphitic structure. To characterise this mineral inclusion, the composition and the structure of the carbonaceous matrix were also investigated.

\subsection{Carbonaceous structure of chars}

As explained previously, the carbonaceous structure plays a major role on the char catalytic activity. In this study, the carbon structure was locally analysed by TEM and Raman spectroscopy. The selected area electron diffraction (SAED) pattern of c.UWP was composed of diffuse rings typical of an isotropic, short-range ordered material (Fig. 2A), and the inter-planar distances obtained 

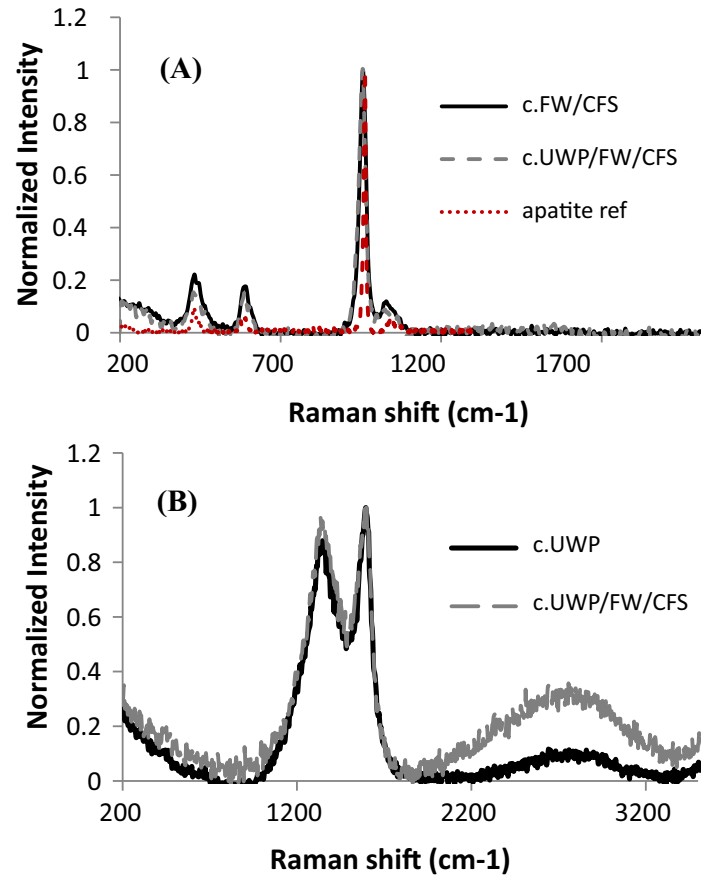

Fig. 5. Normalized Raman spectra of (A) mineral contents in the samples c.FW/CFS and c.UWP/FW/CFS and reference spectra of hydroxyapatite; and (B) carbon bands in the samples c.UWP and c.UWP/FW/CFS.

from this SAED pattern were close to that of loosely organised graphitic material. Moreover, fragments of graphene sheets arranged in a turbostratic structure composed the carbonaceous matrix of c.UWP. The microstructure of c.UWP/FW/CFS and SAED pattern were similar to those of c.UWP, except that nanoporosities were observed in this case (Fig. 2C). HAADF imaging confirmed that these features were indeed pores. Similar nanoporosities were detected at higher magnitude in some regions of c.FW/CFS (Fig. 2B, inset top left). The presence of nanopores on the surface of pyrolysis chars from FW-CFS is in agreement with the literature results that showed that high mesoporous volumes are developed during the pyrolysis of sludge [36]. Fig. 5B corresponds to the normalised Raman spectra of wood-based particles (c.UWP and a piece of wood from c.UWP/FW/CFS) depicted over the quasi whole domain of Raman shift $\left(200-3500 \mathrm{~cm}^{-1}\right)$. The spectra of c.UWP and wood-char particle from c.UWP/FW/CFS presented the same trend, i.e. the $G$ band had higher intensity than the $D$ band. Thus, according to the values of the ratios calculated in Table 4, the graphene sheets and graphene-like sheets would be predominant compared to that of the defects in graphene-like sheets for both samples. However, the D band was relatively more intense in c. $\mathrm{UWP} / \mathrm{FW} / \mathrm{CFS}$, as confirmed by the $\mathrm{I}_{\mathrm{D}} / \mathrm{I}_{\text {tot }}$ and $\mathrm{I}_{\mathrm{D}} / \mathrm{I}_{\mathrm{G}}$ ratios. The increase of the relative intensity of the $\mathrm{D}$ band could be due to an increase of the proportion of large aromatic rings systems [19] and "in plane" imperfections of graphene-like sheets.

The presence of small aromatic rings (deduced from the $\left(\mathrm{I}_{\mathrm{Gr}}+\mathrm{I}_{\mathrm{Vl}}+\mathrm{I}_{\mathrm{Vr}}\right) / \mathrm{I}_{\text {tot }}$ ratio) and aliphatic structures (basing on the $\mathrm{I}_{S} / \mathrm{I}_{\text {tot }}$ ratio) in wood-based particles was not significantly affected by the presence of FW/CFS material during pyrolysis. The $\left(\mathrm{I}_{\mathrm{Gr}}+\mathrm{I}_{\mathrm{Vl}}+\mathrm{I}_{\mathrm{Vr}}\right) / \mathrm{I}_{\mathrm{D}}$ ratio determines the relative proportion of small aromatic rings systems compared to both the large ones and imperfections. The values of the ratio for both samples were above 1.0 indicating the predominance of small aromatic rings systems (Table 4). However the value of the ratio was lower for c.UWP/FW/CFS meaning that the proportion of large aromatic rings systems and imperfections in the graphene-like sheets was slightly higher for this char. This result is in good agreement with the $\mathrm{I}_{\mathrm{D}} / \mathrm{I}_{\mathrm{G}}$
Table 4

Values of various ratios from deconvolution of Raman spectra of wood-based samples.

\begin{tabular}{lll}
\hline Ratio & c.UWP & UWP in c.UWP/FW/CFS \\
\hline $\mathrm{I}_{\mathrm{G}} / \mathrm{I}_{\text {tot }}$ & 0.274 & 0.268 \\
$\mathrm{I}_{\mathrm{D}} / \mathrm{I}_{\text {tot }}$ & 0.222 & 0.241 \\
$\mathrm{I}_{\mathrm{D}} / \mathrm{I}_{\mathrm{G}}$ & 0.810 & 0.899 \\
$\left(\mathrm{I}_{\mathrm{Gr}}+\mathrm{I}_{\mathrm{Vl}}+\mathrm{I}_{\mathrm{Vr}}\right) / \mathrm{I}_{\text {tot }}$ & 0.302 & 0.307 \\
$\mathrm{I}_{\mathrm{S}} / \mathrm{I}_{\text {tot }}$ & 0.097 & 0.102 \\
$\left(\mathrm{I}_{\mathrm{Gr}}+\mathrm{I}_{\mathrm{Vl}}+\mathrm{I}_{\mathrm{Vr}}\right) / \mathrm{I}_{\mathrm{D}}$ & 1.364 & 1.274 \\
\hline
\end{tabular}

ratio discussed previously. Therefore the structure of the carbonaceous matrix in presence of FW/CFS seemed to provide similar fractions of small aromatic rings systems, graphene sheets and graphene-like sheets, and aliphatic chains, while the increase of large aromatic rings systems and structural defects in plane of graphene-like sheets was substantially pronounced. The presence of FW/CFS in the raw mixture increased the presence of minerals and metals. Basically these compounds are supposed to increase the pyrogasification efficiency [34] that may also impact the structure of the carbon matrix. Tay et al. discussed the effect of alkaline and alkali earth metals on the carbon structure in wood-based chars [37]. They observed that the presence of AAEM increased the proportion of small aromatic rings systems in oxidative atmosphere while large aromatic rings systems were favored in reducing atmosphere. In our case, the presence of minerals during the pyrolysis - a slightly reducing atmosphere due to the release of $\mathrm{H}_{2}$ and $\mathrm{CO}$ - increased the proportion of large aromatic rings systems, corroborating the literature results.

\subsection{Catalytic activity of chars}

As explained in introduction, the role of minerals in tar cracking reaction depends on many properties, such as the amount, distribution and speciation. Mineral species like calcium and potassium are known to have significant catalytic activities in tar cracking reactions $[7,38,39]$, as well as iron, manganese, copper and zinc [40]. However, this activity can be inhibited by other mineral species such as silicon and phosphorus.

In this study, different feedstocks have generated various bio chars. This diversity in composition has been confirmed by the multi-scale characterisation. In reality, the highly mineral wastes such as CFS and FW would be separately recovered and treated from wood wastes (UWP). For this reason, the two more realistic materials - c.UWP and c.FW/CFS - were tested as catalysts in a tar cracking process at 400 and $650^{\circ} \mathrm{C}$. Ethylbenzene was selected as surrogate of light aromatic hydrocarbons which represent $40-50 \%$ of tars from biomass [41]. This tar was introduced in the gas flow $\left(\mathrm{N}_{2}: 60 \%\right.$; $\left.\mathrm{CO}: 30 \%\right)$ at a concentration of $40 \mathrm{~g} / \mathrm{N} \mathrm{m}^{3}$. The gaseous effluent was analysed by a micro Gas Chromatograph (R-3000 SRA Instruments). Mass balances were calculated after 90 min of experiment. The details of the experimental procedure are described in Supplementary information. The results showed that (a) ethylbenzene was removed from outflow stream in the presence of both chars and (b) the efficiency increased with the treatment temperature. The analyses of the outflow gas showed that the ethylbenzene was converted into hydrogen, carbon dioxide and other gases (styrene, benzene, ethylene and toluene) meaning that the chars were able to crack ethylbenzene at these temperatures. The catalytic tests also showed that, for identical char volume, the efficiency in ethylbenzene cracking was higher with c.FW/CFS compared to c.UWP. The ethylbenzene conversion at $400{ }^{\circ} \mathrm{C}$ was $3.7 \mathrm{wt} . \%$ and $8.0 \mathrm{wt} . \%$ for c.UWP and c.FW/CFS, respectively, and reached $44.8 \mathrm{wt} . \%$ and $71.4 \mathrm{wt} . \%$ at $650{ }^{\circ} \mathrm{C}$ (Fig. 6). In addition, the deactivation kinetic of c.FW/CFS was slower than that of c.UWP. 


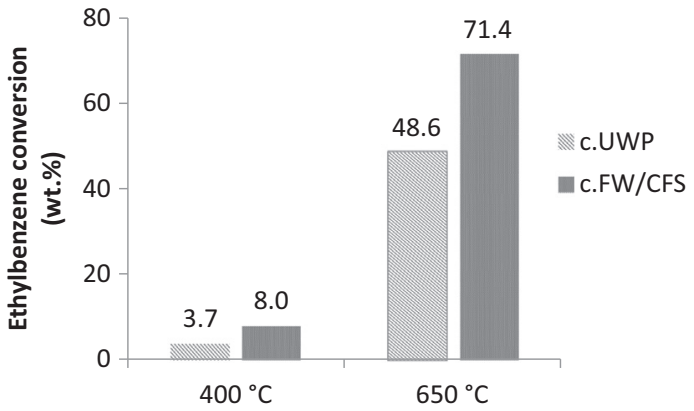

Fig. 6. Efficiency of c. UWP and c.FW/CFS in ethylbenzene elimination at 400 and $650^{\circ} \mathrm{C}$.

On the one hand, the ordered carbonaceous structure can explain the relatively low activity of c.UWP [7]. On the other hand and based on the mineral properties determined in this study, c. UWP logically presented the lowest catalytic activity. Despite the numerous active species in the ash ( $\mathrm{Ca}, \mathrm{K}, \mathrm{Mg}, \mathrm{Fe}$ ), c.UWP had low ash content and presented no crystallised particles on the surface. In addition, the high silicon content in ash (8.0 wt.\%) could inhibit the catalytic activity of active species. On the contrary, the high catalytic activity of c.FW/CFS was mainly related to the high content of ash that should be active in tar cracking reactions, especially due to the large concentration of calcium. Calcium was present in the hydroxyapatite form, but the molar ratio $[\mathrm{Ca}]:[\mathrm{P}]$ calculated from quantitative XRF results indicated that other calcium-based compounds must be present in the char. SEM analyses confirmed that small calcium oxide particles were well dispersed on the char surface, promoting the tar cracking reactions. By studying the distribution of minerals on the char surface, the inhibitory potential of phosphorus could be excluded. Indeed, XRD and Raman analyses evidenced the presence of crystallised hydroxyapatite. Phosphorus was mainly present in c.FW/CFS in this apatitic structure which is thermally stable up to about $1200^{\circ} \mathrm{C}$ [42]. Thus the inhibitory effect of phosphorus, that can melt to encapsulate active species, is avoided. In addition, the "homogeneous" distribution of mineral species within and on the surface of the c.FW/CFS (evidenced by Raman analyses) probably contributed to an extended accessibility for tar molecules. Thus, c.FW/CFS ensured a high catalytic activity towards the cracking reactions.

Catalyst deactivation is often due to the deposition of coke particles produced by tar cracking reactions on the active sites. The high amount of AAEM species in c.FW/CFS could catalyse the gasification reaction of coke thus maintaining a high efficiency in time. Further studies on the catalytic stability would be carried out to confirm or invalidate this behaviour. The char c.UWP/FW/CFS presented properties similar to that of c.FW/CFS, with lower ash rate. One can expect that its catalytic activity would be lower than that of c.FW/CFS but still higher than that of c.UWP.

\section{Conclusions}

This multi-scale approach has been proved to be useful to understand the mineral structure of complex matrices such as chars. Pyrolysis chars were produced from wastes generated on cruise ships - namely used wood pallets (UWP), food waste (FW) and coagulation flocculation sludge (CFS) - having different mineral content. Raw wastes and mixture were pyrolysed. The three resulting chars presented a complex and substantially different mineral amount and content. In order to understand the impact of the pyrolysis and the feedstocks on the char content, a multiscale characterisation of mineral species was performed. SEM and TEM analyses proved that c.UWP/FW/CFS - produced from the mixture of UWP and FW/CFS - had a carbonaceous matrix similar to that of c.UWP, while several oxide particles present on the surface (Ca, P, Al and Si) were also observed on c.FW/CFS. The interactions between the different feedstocks were also found to decrease the release of chlorine during the pyrolysis, as confirmed by the thermodynamic equilibrium calculation. Raman spectra of FW/CFS-based chars highlighted that the crystallised hydroxyapatite particles detected by XRD were not only deposited on the surface but embedded in the char matrix. The two chars with the most different mineral contents were tested as catalysts in a tar cracking process at 400 and $6500^{\circ} \mathrm{C}$ using ethylbenzene as tar surrogate. c. FW/CFS had significantly higher activity than c.UWP and reached a tar conversion of $71.4 \%$ at $650{ }^{\circ} \mathrm{C}$. This higher activity was mainly explained by the mineral content differences described with the multi-scale characterisation. The high ash content as well as the well dispersed and available oxides particles - such as $\mathrm{Ca}$ and $\mathrm{Al}$ oxides - present in c.FW/CFS are known to be active in tar cracking. The presence of hydroxyapatite particles $\left(\mathrm{Ca}_{5}\left(\mathrm{PO}_{4}\right)_{3}(\mathrm{OH})\right)$ embedded in the char matrix has increased the catalytic activity of $c$. FW/CFS, explaining its slower deactivation kinetic by coke deposit compared to that of c.UWP. This char produced from a mixture of wastes (FW and CFS) appeared to be an efficient low-cost and ecofriendly catalyst for tar cracking. The multi-scale characterisation of minerals performed via the combination of various complementary techniques provided relevant information to understand the different catalytic activity of the chars.

\section{Acknowledgement}

This research was supported by the ANR Carnot M.I.N.E.S. The authors acknowledge Eric Chevrel, Katell Chaillou, Laurène Haurie, Marwa Said and Nathalie Lyczko for assistance with experiments.

\section{Appendix A}

See Table A.1.

Table A.1

Raman peak assignment from Asadullah et al., 2010 [18].

\begin{tabular}{|c|c|c|c|}
\hline $\begin{array}{l}\text { Band } \\
\text { name }\end{array}$ & $\begin{array}{l}\text { Band position } \\
\left(\mathrm{cm}^{-1}\right)\end{array}$ & Description & $\begin{array}{l}\text { Bond } \\
\text { type }\end{array}$ \\
\hline $\mathrm{G}_{1}$ & 1700 & Carbonyl group $\mathrm{C}=\mathrm{O}$ & $\mathrm{sp}^{2}$ \\
\hline G & 1590 & Graphite $\mathrm{E}_{2 \mathrm{~g}}^{2}$; aromatic ring; quadrant breathing; alkene $\mathrm{C}=\mathrm{C}$ & $\mathrm{sp}^{2}$ \\
\hline $\mathrm{G}_{\mathrm{r}}$ & 1540 & Aromatics with 3-5 rings; amorphous carbon structures & $\mathrm{sp}^{2}$ \\
\hline $\mathrm{V}_{1}$ & 1465 & Methylene or methyl group; semi circle breathing of aromatic rings; amorphous carbon structures & $\mathrm{sp}^{2} . \mathrm{sp}^{3}$ \\
\hline $\mathrm{V}_{\mathrm{r}}$ & 1380 & Methyl group; semi-circle breathing of aromatic rings; amorphous carbon structures & $\mathrm{sp}^{2}$ \\
\hline $\mathrm{D}$ & 1300 & D band on highly ordered carbonaceous materials; $\mathrm{C}-\mathrm{C}$ between aromatic rings and aromatics with not less than 6 rings & $\mathrm{sp}^{2} \cdot \mathrm{sp}^{3}$ \\
\hline$S_{1}$ & 1230 & Aryl-alkyl ether; para-aromatics & $\mathrm{sp}^{2} \cdot \mathrm{sp}^{3}$ \\
\hline $\mathrm{S}$ & 1185 & $\begin{array}{l}\mathrm{C}_{\text {aromatic }}-\mathrm{C}_{\text {alkyl }} \text {; aromatic (aliphatic) ethers; } \mathrm{C}-\mathrm{C} \text { on hydroaromatic rings; hexagonal diamond carbon } \mathrm{sp}^{3} ; \mathrm{C}-\mathrm{H} \text { on aromatic } \\
\text { rings }\end{array}$ & $\mathrm{sp}^{2} \cdot \mathrm{sp}^{3}$ \\
\hline $\mathrm{S}_{\mathrm{r}}$ & 1060 & $\mathrm{C}-\mathrm{H}$ on aromatic rings; benzene (ortho-di-substituted) ring & $\mathrm{sp}^{2}$ \\
\hline $\mathrm{R}$ & $960-800$ & $\mathrm{C}-\mathrm{C}$ on alkanes and cyclic alkanes; $\mathrm{C}-\mathrm{H}$ on aromatic rings & $\mathrm{sp}^{2} \cdot \mathrm{sp}^{3}$ \\
\hline
\end{tabular}




\section{Appendix B. Supplementary material}

Supplementary data associated with this article can be found, in the online version, at http://dx.doi.org/10.1016/j.fuel.2016.10.089.

\section{References}

[1] McKendry P. Energy production from biomass (part 3): gasification technologies. Bioresour Technol 2002;83:55-63.

[2] Shen Y, Zhao P, Shao Q, Ma D, Takahashi F, Yoshikawa K. In-situ catalytic conversion of tar using rice husk char-supported nickel-iron catalysts for biomass pyrolysis/gasification. Appl Catal B: Environ 2014;152-153:140-51.

[3] Mani S, Kastner JR, Junej A. Catalytic decomposition of toluene using a biomass derived catalyst. Fuel Process Technol 2013;114:118-25.

[4] Woolcock PJ, Brown RC. A review of cleaning technologies for biomass-derived syngas. Biomass Bioenergy 2013;52:54-84.

[5] Di Blasi C. Combustion and gasification rates of lignocellulosic chars. Prog Energy Combust Sci 2009;35:121-40.

[6] Gilbert P, Ryu C, Sharifi V, Swithenbank J. Tar reduction in pyrolysis vapours from biomass over a hot char bed. Bioresour Technol 2009;100:6045-51.

[7] Liu S, Wang Y, Wu R, Zeng X, Gao S, Xu G. Fundamentals of catalytic tar removal over in situ and ex situ chars in two-stage gasification of coal. Energy Fuels 2014:28:58-66.

[8] Wang F-J, Zhang S, Chen Z-D, Liu C, Wang Y-G. Tar reforming using char as catalyst during pyrolysis and gasification of Shengli brown coal. J Anal Appl Pyrol 2014;105:269-75.

[9] Ducousso M, Weiss-Hortala E, Nzihou A, Castaldi MJ. Reactivity enhancement of gasification biochars for catalytic applications. Fuel 2015;159:491-9.

[10] Keown DM, Hayashi J-I, Li C-Z. Drastic changes in biomass char structure and reactivity upon contact with steam. Fuel 2008;87:1127-32.

[11] Fu P, Hu S, Sun L, Xiang J, Yang T, Zhang A, et al. Structural evolution of maize stalk/char particles during pyrolysis. Bioresour Technol 2009;100:4877-83.

[12] Min Z, Yimsiri P, Asadullah M, Zhang S, Li C-Z. Catalytic reforming of tar during gasification. Part II. Char as a catalyst or as a catalyst support for tar reforming. Fuel 2011;90:2545-52.

[13] Klinghoffer NB, Castaldi MJ, Nzihou A. Influence of char composition and inorganics on catalytic activity of char from biomass gasification. Fuel 2015;157:37-47.

[14] Chung WC, Chang MB. Review of catalysis and plasma performance on dry reforming of $\mathrm{CH}_{4}$ and possible synergistic effects. Renew Sustain Energy Rev 2016;62:13-31.

[15] Li X, Li C-Z. Volatilisation and catalytic effects of alkali and alkaline earth metallic species during the pyrolysis and gasification of Victorian brown coal. Part VIII. Catalysis and changes in char structure during gasification in steam. Fuel 2006;85:1518-25.

[16] Mura E, Debono O, Villot A, Paviet F. Pyrolysis of biomass in a semi-industrial scale reactor: study of the fuel-nitrogen oxidation during combustion of volatiles. Biomass Bioenergy 2013;59:187-94.

[17] Downs RT. The RRUFF project: an integrated study of the chemistry, crystallography, Raman and infrared spectroscopy of minerals. In: Program and abstracts of the 19th general meeting of the International Mineralogical Association in Kobe, Japan, 2006; 003-13.

[18] Asadullah M, Zhang S, Min Z, Yimsiri P, Li C-Z. Effects of biomass char structure on its gasification reactivity. Bioresour Technol 2010;101:7935-43.

[19] Li X, Hayashi J-I, Li C-Z. FT-Raman spectroscopic study of the evolution of char structure during the pyrolysis of a Victorian brown coal. Fuel 2006;85:1700-7.

[20] Watts EJ. Ultramicrotomy of carbon-graphite materials for transmission electron microscopy. Metallography 1976;9:43-9.

[21] Ros A, Montes-Moran MA, Fuente E, Nevskaia DM, Martin MJ. Dried sludges and sludge-based chars for $\mathrm{H}_{2} \mathrm{~S}$ removal at low temperature: influence of sewage sludge characteristics. Environ Sci Technol 2006;40:302-9.
[22] Commandré J-M, Lahmidi H, Salvador S, Dupassieux N. Pyrolysis of wood at high temperature: the influence of experimental parameters on gaseous products. Fuel Process Technol 2011;92:837-44.

[23] Yildiz G, Ronsse F, Venderbosch R, van Duren R, Kersten SRA, Prins W. Effect of biomass ash in catalytic fast pyrolysis of pine wood. Appl Catal B: Environ 2015;168-169:203-11.

[24] Elmay Y, Le Brech Y, Delmotte L, Dufour A, Brosse N, Gadiou R. Characterization of chemical surface changes in Miscanthus during pyrolysis. Réc Prog Génie Proc 2014;106.

[25] Dupont C, Nocquet T, Da Costa Jr JA, Verne-Tournon C. Kinetic modelling of steam gasification of various woody biomass chars: influence of inorganic elements. Bioresour Technol 2011;102:9743-8.

[26] Lahijani P, Zainal ZA, Mohamed AR, Mohammadi M. $\mathrm{CO}_{2}$ gasification reactivity of biomass char: catalytic influence of alkali, alkaline earth and transition metal salts. Bioresour Technol 2013;144:288-95.

[27] Jiang L, Hu S, Xiang J, Su S, Sun LS, Xu K, et al. Release characteristics of alkali and alkaline earth metallic species during biomass pyrolysis and steam gasification process. Bioresour Technol 2012;116:184-278.

[28] Okuno T, Sonoyama N, Hayashi JI, Li CZ, Sathe C, Chiba T. Primary release of alkali and alkaline earth metallic species during the pyrolysis of pulverized biomass. Energy Fuels 2005;19:2164-71.

[29] Nzihou A, Stanmore B. The fate of heavy metals during combustion and gasification of contaminated biomass-a brief review. J Hazard Mater 2013;256-257:56-66.

[30] Du S, Wang W, Shao J, Yang H, Xu G, Chen H. Releasing behavior of chlorine and fluorine during agricultural waste pyrolysis. Energy 2014;74:295-300.

[31] Li W, Lu H, Chen H, Li B. The volatilization behavior of chlorine in coal during its pyrolysis and $\mathrm{CO}_{2}$-gasification in a fluidized bed reactor. Fuel 2005;84:1874-8.

[32] Quyn DM, Wu H, Battacharya SP, Li CZ. Volatilisation and catalytic effects of alkali and alkaline earth metallic species during the pyrolysis and gasification of Victorian brown coal. Part II. Effects of chemical form and valence. Fuel 2002;81:151-8.

[33] Nzihou A, Sharrock P. Calcium phosphate stabilization of fly ash with chloride extraction. Waste Manage 2002;22:235-9.

[34] Nzihou A, Stanmore B, Sharrock P. A review of catalysts for the gasification of biomass char, with some reference to coal. Energy 2013;58:305-17.

[35] Hognon C, Dupont C, Grateau M, Delrue F. Comparison of steam gasification reactivity of algal and lignocellulosic biomass: influence of inorganic elements. Bioresour Technol 2014;164:347-53.

[36] Wallace R, Seredych M, Zhang P, Bandosz TJ. Municipal waste conversion to hydrogen sulphide adsorbents: investigation of the synergistic effects of sewage sludge/fish waste mixture. Chem Eng J 2014;237:88-94.

[37] Tay HL, Kajitani S, Wang S, Li C-Z. A preliminary Raman spectroscopic perspective for the roles of catalysts during char gasification. Fuel 2014; $121: 164-72$.

[38] DeGroot WF, Shafizadeh F. Kinetics of gasification of Douglas Fir and Cottonwood chars by carbon dioxide. Fuel 1984;63:210-6.

[39] Moilanen A, Mühlen HJ. Characterization of gasification reactivity of peat char in pressurized conditions: effect of product gas inhibition and inorganic material. Fuel 1996;75:1279-85.

[40] Shen Y, Yoshikawa K. Recent progresses in catalytic tar elimination during biomass gasification or pyrolysis - a review. Renew Sustain Energy Rev 2013;21:371-92.

[41] Coll R, Salvado J, Farriol X, Montané D. Steam reforming model compounds of biomass gasification tars: conversion at different operating conditions and tendency towards coke formation. Fuel Process Technol 2001;74:19-31.

[42] Pham Minh D, Galera Martinez M, Nzihou A, Sharrock P. Thermal behavior of apatitic calcium phosphates synthesized from calcium carbonate and orthophosphoric acid or potassium dihydrogen orthophosphate. J Therm Anal Calorim 2012;112:1145-55. 